\title{
Food Safety on the Farm: Good Agricultural Practices and Good Handling Practices-Water ${ }^{1}$
}

\author{
Jaysankar De, Christopher R. Pabst, Jessica Lepper, Renée Goodrich-Schneider, and Keith R. \\ Schneider ${ }^{2}$
}

As part of the Food Safety on the Farm series, a collection that reviews the generally recognized principles of GAPs as they relate to produce, primarily at the farm level and with particular focus on fresh Florida crops and practices, this publication focuses on GAPs and GHPs relating specifically to water use. The publications in this series can be found online at the EDIS website at http://edis.ifas.ufl.edu/ topic_series_food_safety_on_the_farm.

\section{Introduction}

The principles of Good Agricultural Practices (GAPs) were introduced by the US Food and Drug Administration (FDA) in the 1998 Guidance for Industry Guide to Minimize Microbial Food Safety Hazards for Fresh Fruits and Vegetables (FDA 1998). This guidance document for the fresh fruit and vegetable industry provided general guidelines for reducing the risk of contamination of fresh produce by microbial organisms. In response to this guidance, the United States Department of Agriculture (USDA) formally implemented the Good Agricultural Practices \& Good Handling Practices (GAPs and GHPs) audit verification program.

The USDA incorporated the Produce GAPs Harmonized Food Safety Standard into its GAP \& GHP audit program in 2011. The USDA further combined these two into a harmonized GAPs (H-GAPs) program in May 2018. To make the oversight of food safety stronger and more efficient, the FDA and the USDA announced the alignment of the USDA H-GAP with the requirements of the FSMA's Produce Safety Rule (PSR) in June 2018. Since H-GAP is not equivalent to the Global Food Safety Initiative (GFSI), the USDA augmented the H-GAP audit to meet GFSI equivalence standards. The new USDA Harmonized GAP Plus+ audit is the only USDA GAP audit recognized as being GFSI technically equivalent. Regardless, all these programs adhere to the same basic principles of GAPs.

Under the new Food Safety Modernization Act (FSMA), GAPs are the foundation of the PSR. Up until the PSR, GAPs programs have been voluntary, imposed by the industry or buyers. Exceptions are the Florida Tomato Good Agricultural Practices (T-GAP) and Tomato Best Management Practices (T-BMP) regulations, which are state laws regulating the safe production of tomatoes. The current PSR mandates all non-exempt operations to follow the new FSMA federal guidelines (FDA 2017), except for exempt commodities (as outlined in the regulation) and for those producers exporting to foreign countries. In those circumstances, voluntary GAPs programs may still be required by buyers or trade organizations.

1. This document is FSHN06-02, one of a series of the Food Science and Human Nutrition Department, UF/IFAS Extension. Original publication date November 2006. Revised April 2010 and March 2019. Visit the EDIS website at for the currently supported version of this publication.

2. Jaysankar De, postdoctoral research associate; Christopher R. Pabst, graduate student; Jessica Lepper, training specialist; Renée M. GoodrichSchneider, professor; and Keith R. Schneider, professor; Food Science and Human Nutrition Department, UF/IFAS Extension, Gainesville, FL 32611. 
The aim of both the mandatory PSR and the voluntary GAPs program is to reduce the foodborne illness burden associated with produce (FDA 2018b, 2019). The FDA has compiled information from the Centers for Disease Control and Prevention (CDC) data regarding produce-associated outbreaks that occurred between 1996 and 2010 where contamination was likely to have happened early in the production chain, during growing, harvesting, manufacturing, processing, packing, holding, or transportation (CDC 2018; FDA 2018b). An updated report from the CDC estimates that produce accounted for $51.6 \%(21,280$ of 41,269$)$ of all foodborne outbreaks in the United States from 1998 to 2016 (CDC 2018).

Water is one of the most critical components of food safety on the farm and in both pre- and post-harvest handling and processing. Water has the potential to transmit both chemical and biological hazards to fresh produce. It is used in every phase of operation: irrigation, transplant establishment, application of pesticides and fertilizers, frost protection, product rinsing and washing, direct processing, facility cleaning, cooling operations, and personal hygiene for workers. The application of contaminated water at any of these points can introduce pathogens that could potentially reach the consumer.

The final PSR has tiered compliance dates (based on average annual produce sales) for non-exempt produce other than sprouts. The first major compliance date for large farms, excluding sprout operations, began on January 26,2018 . For small and very small businesses, the earliest compliance date is set to January 28, 2019, and January 27, 2020 , respectively. For agricultural water requirements, compliance dates are extended for an additional four years. However, the US Food and Drug Administration (FDA) has announced that routine inspections associated with the PSR will not begin until the spring of 2019. Large sprout operations were required to meet an earlier compliance date on January 26, 2017. For small and very small sprout operations, the earliest compliance date was set to January 26, 2018, and January 28, 2019, respectively (FDA 2018a).

This fact sheet will focus on those activities and facilities that will be operational under GAPs as outlined in the Guide to Minimize Microbial Food Safety Hazards for Fresh Fruits and Vegetables (FDA 1998; FDA 2008). This fact sheet will specifically address those GAPs that pertain to water usage. Additional UF/IFAS Extension fact sheets in this series focus on other specific aspects of the GAPs program and how they relate to Florida crops and practices.

\section{Microbial Hazards}

Water can be a carrier of many pathogenic strains of microorganisms, including but not limited to E. coli O157:H7, Salmonella, Shigella, Cryptosporidium, Cyclospora, and hepatitis A. Even small amounts of contamination with some of these organisms can result in a foodborne illness. It is often difficult to identify with certainty the source of microbial contamination for fresh produce. In 2007, the Centers for Disease Control and Prevention (CDC) reported four Salmonella outbreaks associated with tomatoes between the years 2005 and 2006. Several possible causes for these outbreaks were given, ranging from contaminated irrigation water to wildlife intrusion (CDC 2007). Growers and packers must take a proactive role in minimizing these microbial hazards whenever they can (FDA 1998; FDA 2019).

\section{How to Control Potential Hazards}

The quality of fresh produce is affected by many factors associated with water. The quality of the water used, the ways in which it is used, the type of crop being grown, and the growing conditions all influence and affect the potential for contamination. Water quality is extremely important when water comes into direct contact with the harvestable portion of produce. Better quality controls may be necessary in these cases than in those where water makes minimal contact with the harvestable portion of produce (FDA 1998; FDA 2019).

Other factors that influence the potential for a pathogen to get onto or into fresh produce include the condition and type of crop, the length of time between pathogen contact and harvest, and post-harvest handling practices. Produce with large surface areas (e.g., lettuce, spinach, etc.), rough surfaces (e.g., cantaloupe), or stem scars (e.g., tomatoes) may be at greater risk, especially if pathogen contact occurs close to harvest and/or during post-harvest handling. Some growers/packers in the produce industry use antimicrobial chemicals to maintain water quality and/or minimize surface contamination (FDA 1998; FDA 2019).

The following areas have been identified by the FDA as important when assessing water quality. By controlling these areas, a grower/packer/processor may be able to minimize microbial food-safety hazards related to water usage in specific operations (FDA 1998; FDA 2019). 


\section{Agricultural Water}

Water quality should be safe for its intended use. Where water quality is unknown or cannot be controlled, growers should use other good agricultural practices to minimize the risk of microbial contamination (FDA 1998; FDA 2019).

Agricultural water quality varies. For example, water that is clean one day may become contaminated the next, perhaps by wastewater discharge or polluted runoff from upstream livestock operations. Surface water contamination may also affect groundwater (e.g., surface water could infiltrate through an old well with a cracked casing) (FDA 1998; FDA 2019).

To help ensure high-quality water, make sure wells are properly constructed and protected, and/or treat water prior to use to reduce microbial loads. If the quality of the water is not consistent (e.g., water from a shallow well or temporary wells), alternative application methods that minimize or avoid water-to-produce contact might be necessary. Remember, not all interventions are equally effective or applicable to your produce operation. Review your operations to gain a clear understanding of which changes are the most feasible and will have the greatest impact (FDA 1998).

The PSR establishes two sets of criteria for microbial water quality, one for pre-harvest and one for harvest and postharvest. Both are based on the presence of generic E. coli, which can indicate the presence of fecal contamination (FDA 2019).

- For all pre-harvest agricultural water uses, the geometric mean (GM) of generic E. coli is 126 or fewer colony forming units (CFU) per $100 \mathrm{~mL}$ of water. Another value, the statistical threshold value (STV) must be 410 CFU or fewer of generic E. coli in $100 \mathrm{~mL}$ of water.

- During harvest and post-harvest, no detectable generic $E$. coli per $100 \mathrm{ml}$ of water are allowed. This includes water for washing hands during and after harvest, ice making, fluming, hydrocooling, etc.

These criteria consider variability and allow occasional high counts of generic $E$. coli in the appropriate context. These criteria are intended as a water management tool for use in understanding the microbial quality of agricultural water over time and determining a long-term strategy for use of water sources while growing produce (other than sprouts). Farmers with agricultural water that does not initially meet the microbial criteria have options. They could allow time for potentially dangerous microbes to die off in field between last irrigation and harvest or between harvest and commercial activities (e.g., washing) or end of storage, within appropriate limits. Another option would be to treat the contaminated water before use to eliminate the pathogens at their source. These corrective actions are required as soon as is practicable but no later than the following year.

\section{General Considerations}

There are many sources of agricultural water. Flowing surface water can come from rivers, streams, irrigation ditches, and open canals. Water can also come from impoundments, such as ponds, reservoirs, lakes, and wells. Lastly, water may be obtained from a municipal supply. Generally speaking, groundwater is less likely to be contaminated than surface water, but under certain conditions, shallow, improperly constructed, or older wells may become contaminated from surface water (FDA 1998). In order to prevent contamination:

- Identify the source and distribution of water used and be aware of its relative potential for being a source of pathogens.

- Maintain wells in good working condition.

- Review existing practices and conditions to identify potential sources of contamination.

- Be aware of current and historical uses of land. As water is typically a shared resource, it is important to be aware of hazards from potential contamination that you may not control.

- Make sure that feedlots, animal pastures, and dairy operations in the region use and maintain fences or other barriers to minimize animal access to shared water sources.

- Find out if manure is applied to land by many farms in the region that could contaminate your agricultural environment by runoff, wind drift, animal intrusion, or even unsanitary transportation.

- Find out how local rainfall patterns and topography affect the likelihood that contaminated runoff from these operations will reach surface waters.

- Make sure that controls are in place to minimize contamination of agricultural waters from other farm or animal operations.

- Consider practices that will protect water quality. These practices include, but are not limited to, protecting surface waters, wells, and pump areas from uncontrolled livestock or wildlife access. Also, it is important to consider implementing soil and water conservation 
practices, such as diversion berms and runoff control structures, that help prevent polluted runoff water from contaminating agricultural water sources and crops.

- Consider irrigation-water quality and use. Make sure to minimize the potential for contaminated water to contact the harvestable portion of the crop.

\section{Microbial Testing of Agricultural Water}

Microbial testing gives growers only a "snapshot" of water quality. For example, a single test performed last month would have limited predictive value for this month if a rainfall event happened to wash cattle runoff into your tomato field. Water quality can vary seasonally or even hourly depending on circumstances. Growers who are concerned about water quality should first focus their attention on GAPs to maintain and protect the quality of their water sources (FDA 2019).

However, periodic testing still can be a useful tool. Growers can test their water supply for microbial contamination on a periodic basis, using standard indicators of fecal contamination, such as E. coli. Make sure these tests are performed by a qualified commercial, state, or local government laboratory (FDA 2019).

Even if your results do not show bacterial safety concerns, this does not necessarily indicate an absence of protozoa and/or viruses that can cause a foodborne illness. Water quality, especially surface water quality, can vary with time, and most tests will not tell you if specific pathogens are present in low numbers. Growers should consult local water-quality experts, such as specialists from state or local environmental protection or public health agencies, county Extension offices and research centers, or landgrant universities, for advice that is appropriate for their individual operations (FDA 1998; FDA 2019).

In the final PSR, testing frequency of untreated water is based on the water source (surface or ground). Untreated surface water is considered the most vulnerable to external influences. The FDA requires farms to do an initial survey of at least 20 samples as close to harvest as practicable, over the course of two to four years. The geometric mean (GM) and the statistical threshold value (STV) from these samples are calculated (GM and STV figures are known as microbial quality profile) to see if the water meets the minimum criteria. After the initial survey is done, an annual survey of minimum five samples per year is required to update the calculations of the rolling GM and STV (FDA 2019).
For untreated ground water that is applied directly to produce (other than sprouts), the initial survey must include a minimum of four samples collected as close to harvest as practicable during the growing season or over a one-year period. The GM and STV are calculated from the initial survey to determine if the water meets required standards. After the initial survey is completed, an annual survey of a minimum of one sample per year is required to update the calculations of the rolling GM and STV. For untreated groundwater where no detectable generic E. coli is allowed, the FDA requires farms to initially test the untreated groundwater at least four times during the growing season or over a period of one year. If the results from the initial tests show no detectable generic E. coli, farms can test once annually thereafter. If the results from the initial tests fail to meet the microbial quality criterion, the farm must resume testing at least four times per growing season (FDA 2019).

No testing is required for agricultural water received from public water systems or supplies that meet requirements established in the rule (provided that the farm has Public Water System results or certificates of compliance demonstrating that the water meets relevant requirements), or if the water is treated in compliance with the rule's treatment requirements.

\section{Processing Water}

Fruits and vegetables are highly susceptible to contamination during post-harvest handling due to the high degree of water-to-produce contact. Water used for all aspects of processing should be of such quality that it cannot contaminate produce. Water can be useful in reducing potential contamination, but it may also serve as a source of contamination or cross-contamination. If processing water is reused, plant and human pathogens can build up, resulting in the contamination of a large batch of produce. Practices should be instituted to ensure that water quality is adequate both at the start and at the end of all post-harvest processes (FDA 2019). The following practices are recommended:

- In series of processes where water is reused, water flow should be counter to the movement of produce through different operations so that the most processed produce is always exposed to the cleanest water.

- Ensure that water is maintained in a condition suitable for its intended application, through regular treatment with disinfectant chemicals, the levels of which are closely monitored. 
- Ensure routine water-quality testing of ice intended for use on/with fresh produce.

\section{General Considerations}

Follow good manufacturing practices (GMPs) to minimize microbial contamination from processing water. GMPs for water used for food and food contact surfaces in processing facilities are in Title 21 of the Code of Federal Regulations (CFR), sections 117.37(a) and 117.80(a)(1). These GMPs are in place for all manufacturers, packers, and processors of food products, and are available online at (ECFR 2018).

- Water quality needs may vary depending on where the water is used during the series of processes.

- Contamination prevention is preferred over adding antimicrobial chemicals post-contamination. Always remember that prevention is better than a cure.

Consider practices that will ensure and maintain water quality. Such practices may include:

- Performing periodic water sampling and microbial testing.

- Changing water as necessary to maintain sanitary conditions. Develop standard operating procedures or sanitary operating plans (SOPs), including water change schedules, for all processes that use water.

- Cleaning and sanitizing water contact surfaces (such as dump tanks, flumes, wash tanks, and hydrocoolers) as often as necessary to ensure the safety of produce.

- Installing backflow prevention devices and legal air gaps as needed (such as between potable water fill lines and dump-tank drain lines) to prevent the contamination of clean water by potentially contaminated water.

- Routinely inspecting and maintaining equipment designed to assist in maintaining water quality, such as chlorine injectors, filtration systems, and backflow prevention devices, in order to ensure efficient operation.

- Minimizing the accumulation of organic material in wash water. In some cases, the filtration of recirculating water or the use of a net to remove plant material and other debris from tanks may further prevent the accumulation of organic material.

\section{Antimicrobial Chemicals}

Another point to remember is that the best offense may be a good defense. Preventing a pathogen from getting onto your product in the first place is preferable over trying to remove one. Antimicrobial chemicals used in processing water can be useful in reducing microbial build-up and may reduce the potential for cross-contamination (ECFR 2018; FDA 1998).

The effectiveness of an antimicrobial agent depends on many factors too numerous to mention here. For more information, refer to Chlorine Use in Produce Packing Lines (http://edis.ifas.ufl.edu/ch160), a fact sheet by Ritenour et al. (2002). There are many different chemicals, such as sodium hypochlorite (food-grade bleach), ozone, ultraviolet radiation, chlorine dioxide, and organic acids (such as lactic and acetic acids) and other methods one can use. Operators should consider which options are most appropriate for their individual operations. Contact chemical companies that sell antimicrobial chemicals for additional technical assistance (FDA 1998; FDA 2019). When using antimicrobial chemicals, the following recommendations are in order:

- Follow the manufacturer's directions for proper mixing of antimicrobial chemicals to obtain proper concentrations, and do not exceed manufacturers' suggested allowable levels for antimicrobial chemicals in wash water. Disproportionate concentrations of antimicrobial chemicals can be harmful to workers and can possibly pose an avoidable hazard for consumers.

- Consistent monitoring and record-keeping of antimicrobial levels will help ensure that appropriate levels are maintained throughout the operation.

- After contact between produce and processing water that contains antimicrobial chemicals, make sure to apply a clean rinse with water of appropriate quality to remove treatment residues as needed, in compliance with the manufacturer's directions.

\section{Wash Water}

Produce may be washed at several junctures, including in the field, in a cooling facility, or in the processing facility itself. Washing the surface of fresh produce can reduce the overall burden of microbial foodborne safety hazards. No washing process can remove all pathogens, but every additional cleansing step helps. Since a lot of microbial contamination is on the surface of fruits and vegetables, proper washing can be an important part of the postharvest process (FDA 2019), though it is not considered a kill step. The main function is to prevent cross-contamination between contaminated and non-contaminated produce.

As mentioned, the reason for extra care at this step is that if pathogens are not removed or controlled here, they can contaminate (cross-contamination) other produce and processing equipment, creating a bigger problem. Several 
postharvest processes (such as hydrocooling, use of dump tanks, and flume transport) use a lot of water; thus there is a high risk of cross-contamination if a sanitizer is not used. Packers should follow GMPs to maximize the potential for these processes to assist in cleaning produce (ECFR 2018).

- Use appropriate wash methods; vigorously washing produce will have greater efficacy in pathogen removal. For easily bruised produce, other options are available, including submersion, spray, or both.

- Use a series of washes if appropriate to the operation in question. An initial wash may be useful in the removal of the bulk of field soil, followed by one or more washes containing an antimicrobial chemical.

- Maintain the efficacy of wash treatments.

- Consider the wash water's temperature for certain produce. In general, wash water should not be at a cooler temperature than the produce being washed, to prevent the internalization of pathogens that may be present in the wash water. The recommended temperature differential can be accomplished by heating the water or by air cooling the produce before washing.

- Consider alternative treatments for water-sensitive produce. Brushing, scraping, and blowing air can all be used to clean produce that cannot tolerate water.

\section{Cooling Operations}

Cooling is a step that is often overlooked when trying to reduce microbial contamination. Different methods can be employed, including the uses of water, ice, and forced-air cooling. The best method depends on the fruit or vegetable being processed. In most cases, air cooling-particularly vacuum cooling or the use of fans-has the lowest risk of contaminating your product. If you use water and/or ice, remember that improperly sanitized water is a potential source of contamination. If you reuse your water in produce cooling, remember that microbial contamination and organic load can build up (FDA 2019). Good practices may include the following:

- Cool the product quickly and maintain temperatures that promote optimum produce quality.

- Maintain air-cooling equipment and cooling areas.

- Consider the use of antimicrobial chemicals in cooling water.

- Keep water and ice clean and sanitary.

- Manufacture, transport, and store ice under sanitary conditions.

- Equipment should be clean and sanitized.
- Prevent condensate and/or defrost water of evaporatortype cooling systems (e.g., vacuum cooling, cold storage) from dripping onto produce or any surfaces with which produce may come into contact.

- Store similar commodities together (according to level of processing) to avoid cross-contamination.

- Locate temperature-monitoring devices in the warmest area of the refrigerator unit and calibrate them on a regular basis.

\section{References}

Centers for Disease Control and Prevention (CDC). 2007. Multistate Outbreaks of Salmonella Infections Associated with Raw Tomatoes Eaten in Restaurants --- United States, 2005--2006. http://www.cdc.gov/mmwr/preview/ mmwrhtml/mm5635a3.htm. Accessed on February 5, 2019.

Centers for Disease Control and Prevention (CDC). 2018. National Outbreak Reporting System (NORS). https:// wwwn.cdc.gov/norsdashboard/. Accessed on February 5, 2019.

Electronic Code of Federal Regulations (e-CFR). 2018. Current Good Manufacturing Practice in Manufacturing, Packing, or Holding Human Food. https://www.ecfr.gov/ cgi-bin/text-idx?SID=adf6f37d920ca67a63bbed513dc16499 $\& m c=$ true \&tpl=/ecfrbrowse/Title21/21cfr117_main_02.tpl. Accessed on February 5, 2019.

Food and Drug Administration (FDA). 1998. Guide to Minimize Microbial Food Safety Hazards for Fresh Fruits and Vegetables. https://www.fda.gov/regulatory-information/ search-fda-guidance-documents/guidance-industry-guideminimize-microbial-food-safety-hazards-fresh-fruits-andvegetables. Accessed on February 5, 2019.

Food and Drug Administration (FDA). 2008. Guidance for Industry: Guide to Minimize Microbial Food Safety Hazards of Fresh-cut Fruits and Vegetables. https://www.fda.gov/ Food/GuidanceRegulation/GuidanceDocumentsRegulatoryInformation/ProducePlantProducts/ucm064458.htm. Accessed on February 5, 2019.

Food and Drug Administration (FDA). 2017. Food Safety Modernization Act. http://www.fda.gov/Food/GuidanceRegulation/FSMA/default.htm. Accessed on February 5, 2019. 
Food and Drug Administration (FDA). 2018a. FSMA

compliance dates. https://www.fda.gov/downloads/Food/

GuidanceRegulation/FSMA/UCM568798.pdf

Food and Drug Administration (FDA). 2018b. Produce

Safety Standards. https://www.fda.gov/food/guidanceregulation/fsma/ucm304045.htm. Accessed on February 5,

2019.

Food and Drug Administration (FDA). 2019. FSMA

Final Rule on Produce Safety. http://www.fda.gov/Food/

GuidanceRegulation/FSMA/ucm334114.htm. Accessed on

February 5, 2019.

Ritenour, M.A., S.A. Sargent, and J.A. Bartz. 2002. Chlorine Use in Produce Packing Lines. HS-761. Gainesville: University of Florida Institute of Food and Agricultural Sciences. http://edis.ifas.ufl.edu/CH160. Accessed on February 5, 2019. 